\title{
INTERNET-BASEDLEARNING APPROACH FOR ENGLISH LANGUAGEACQUISITION
}

\author{
Kumar M. Agarwal \\ RBS Riga Technical University \\ L. Novickis \\ Riga Technical University
}

\begin{abstract}
This article explores teachers' and students' benefits of using Internet-based Language Learning(IBLL) which includes teaching the English Language. This paper reports on the advantages and disadvantages of using internet resources and computers to learn and teach the English language. Until quite recently, Internet-based Language Learning (IBLL) was a topic of relevance mostly to those with a special interest in that area. Recently, though, the internet has become so widespread in educational institutions and homes and its uses have expanded so dramatically that the majority of the English language teachers have started the implications of the Internet for language learning. This article provides brief overview of how internet resources can be used for language teaching. It focuses not on a technical description of software, but rather on the pedagogical questions that teachers should consider in using internet resources.
\end{abstract}

Keywords: Internet resources, online quizzes, language learning and teaching approach

\section{Introduction}

Nowadays Internet-based Language Learning (IBLL) is becoming the most innovative area in the practice of the English language teaching and learning (Agarwal, 2008). Keeping students interested and engaged in the current topic or activity is a daily challenge for teachers in the classroom. IBLL provides new possibilities for assisting teachers to successfully meet this challenge.

In the last few years the number of teachers using IBLL has increased significantly. Although the potential of the internet resources for educational use has not been fully explored, yet and many educational institutions still make limited use of computers and internet resources, it is obvious that we have entered a new information age in which teaching and learning of English as a Foreign Language completely based on information technologies. The development of the Internet brought about a revolution in the teachers' perspective, as the teaching tools and resources offered by the Internet are more reliable and authentic(Agarwal, 2009). Nowadays the Internet is gaining immense popularity in English language teaching and more and more educators and learners are embracing it to benefit from it.

\section{Advantages and Disadvantages of IBLL}

There are a lot of advantages and disadvantages of IBLL, but disadvantages are not as many as advantages. There are a lot of challenges faced by a teacher instructing class as it is difficult to keep good discipline going in class and 
teachers have to provide for more students of different abilities who want to learn the language at different speeds and in different ways.

\section{Advantages of IBLL}

- There are a lot of advantages of Internet-based language learning:

- IBLL provides students with a lot of genuine educational materials, games, simulations, dictionaries, etc.

- IBLL can lead to autonomy, as learners exercise control over the learning process and are little dependent on the teacher (Agarwal, 2009).

- Computers present materials in various ways. Electronic things on the screen are perceived to be more attractive, and less indelible than traditional methods of learning languages (Agarwal, 2010).

- IBLL makes students use of an online reference allowing them to consult electronic resources beyond those of grammar-check, dictionary and thesaurus (Agarwal, 2011).

- Computers use various colors, types and sizes of letters.

- IBLL provides distance education (Agarwal, 2008).

- Computers free students from the limitations of traditional writing tools (Agarwal, 2011).

- Computers transform learning languages from a traditional passive exercise to an interactive experience of discovery and exploration (Agarwal, 2008).

- Computers are flexible and untiring (Agarwal, 2008).

- Computers help language learners create, analyze, and produce information and ideas more easily and efficiently (Agarwal, 2009).

- Computers rapidly and accurately check answers and give immediate feedback if they are programmed to do so. Computers confirm that an answer is correct, give the correct answer or a hint if the answer is incorrect, etc.

- Computers clock can be used to time the students' work, limit the amount of time allowed to read a passage or do an exercise or a set of exercises, etc.

- Language Learning can be individualized using computers. Students study materials related to their individual goals and what they need or are interested in, with the appropriate difficulty level and at their own pace (Agarwal, 2009).

- Teachers and students can learn English on the Internet wherever and whenever it is needed not only in class at the fixed time and place (Agarwal, 2010).

- Computers keep records accurately. Teachers can keep track of individual or class scores and times (Agarwal, 2010).

- Computers help students realize their full potential to collaborate as a team to accomplish tasks more effectively (Agarwal, 2009). 
- Computers enable students to electronically monitor and control the language learning process.

- Computers enable teachers to quickly retrieve students' electronic writing for future analyses and grading.

- Computers calculate quickly and accurately. They help teachers get the total score, average, and standard deviation and statistically analyze individual student and class results(Agarwal, 2011).

- The internet gives an opportunity to shy students to express themselves and ask questions electronically(Agarwal, 2008).

- Using multi-media materials, computers display written text and use sounds, still pictures, and video, students feel things are more real and more easily understood.

\section{Disadvantages of IBLL}

Besides having a lot of advantages, there are several disadvantages of IBLL. IBLL is not applied everywhere successfully because there are several barriers that do not let it be applied in the educational programs. The barriers of IBLL can be classified in the following common categories:

- Both students and teachers must be computer-literate because using IBLL means being good at computers.

- Sometimes available internet resources are difficult to use despite providing a good manual. No matter how simple computers and the internet are, students still need to learn a great deal in order to use them properly (Agarwal, 2008).

- Internet resources have limitations on their memory, speed, methods of input and output, etc. Internet resources for language acquisition are still imperfect.

- Information is usually input by typing it in, so to use a computer efficiently, it is necessary to know how to type. Nowadays there are a few internet resources with voice recognition but they are not very popular for not being well-developed (Agarwal, 2009).

- In general all internet sites do what they are programmed to do. All internet resources have some limitations. For example, some language learning resources show the final score after taking a quiz without any further explanation of mistakes.

- Most internet resources cannot do exactly what a user wants them to do (Agarwal, 2008).

- Computers cannot handle user's unexpected requests and requirements as computers may perform the things they are designed to do (Agarwal, 2010). 
- Computers and access to the internet are expensive.In addition, there is a great deal of additional equipment which is needed. Low budget schools and low-income students cannot usually afford it.

- A special classroom is also necessary, along with technicians to keep the computers and the network working properly (Agarwal, 2009).

- Computers break down, and they may have technical problems, which costs money.

- It is also necessary to train teachers in order to make them ready to explain the things better and use Information Technologies (Agarwal, 2011).

\section{Research: Language learning approaches}

There are three approaches to teach and learn languages (Figure 1):

1. Classical approach (Teacher + Students)

2. Modern approach (Computer + Students)

3. Ultramodern approach (Teacher + Computer + Students)

A research was carried out at Information Systems Management Institute (ISMA) to find out the best approach. The participants in this study were 15 non-native English speakers with the intermediate level of English language knowledge who were attending the second year of their bachelor degree program, where I was their ESL instructor. The participants, almost equally divided between male and female, ranged in ages from 20-25. The home country of the participants was Latvia. The participants were divided into three groups with five participants each. One English grammar topic (Present Perfect and Past Simple) was chosen to be explained.

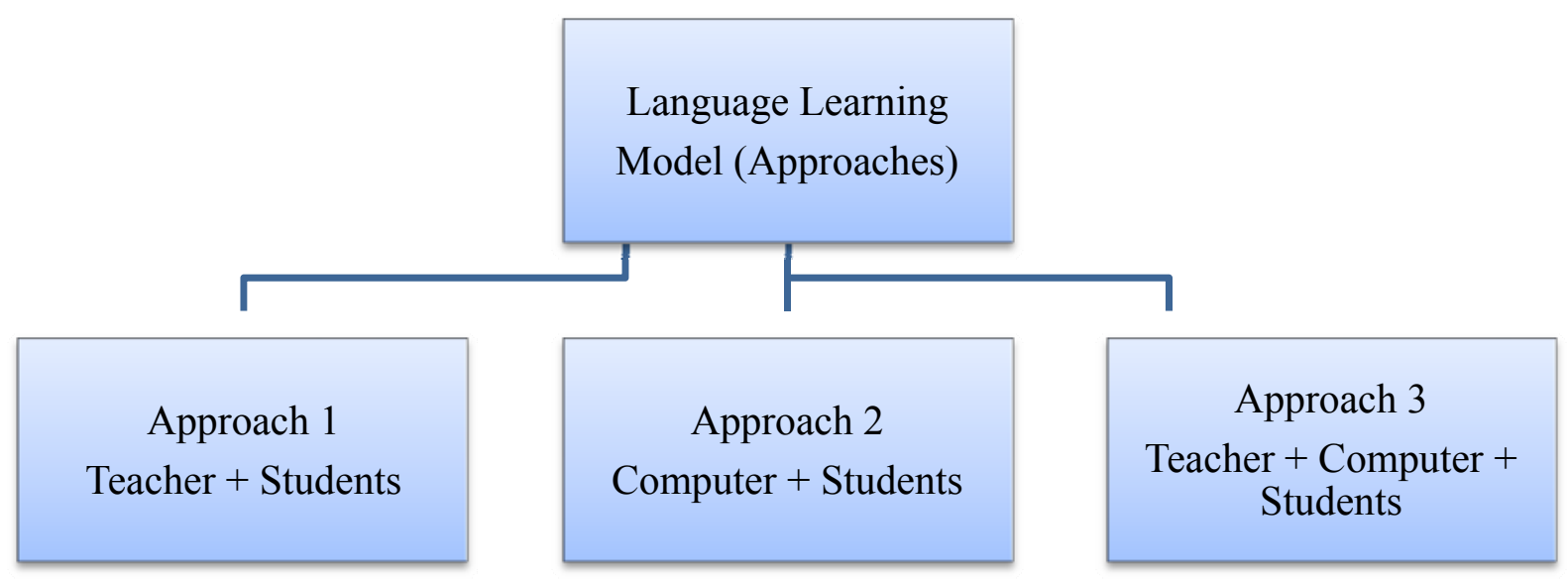

Figure 1 Language learning approaches

Approach 1 (Teacher + students): The teacher explained the topic and the students were asked to answer 50 questions. The Students' score is shown in figure 2 . 


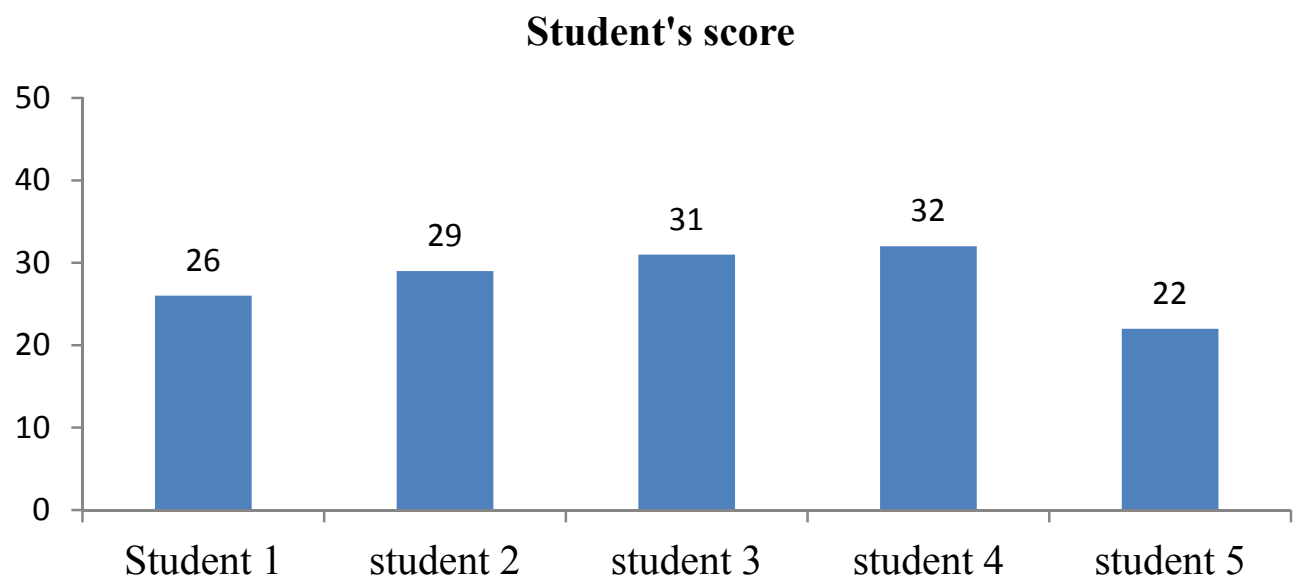

Figure 2 Students' score within approach 1

The graph shows the number of correct answers given by each student within approach 1 . It can be clearly seen that the students did not do very well on the test and the maximum score does not exceed $64 \%$.

Approach 2(Computer + students): Within this approach,the students were asked to learn and understand grammar explanation on the internet and asked to answer 50 online questions. Their score is shown in figure 3.

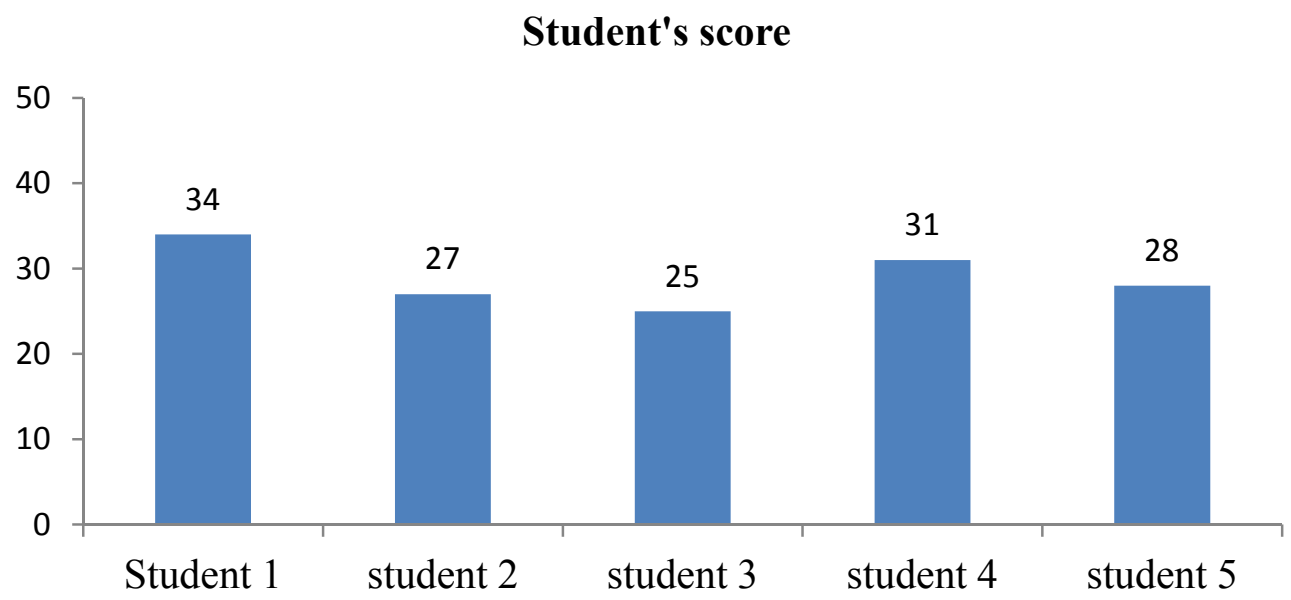

Figure 3 Students' score with approach 2

The graph shows the number of correct answers given by each student within approach 2 . It can be clearly seen that the students did the test slightly better than in approach 1 and the maximum score is $68 \%$.

Approach 3 (Teacher + students + computer): Within this approach, the topics were explained not only by the teacher but also by a computer and later they were asked to answer 50 questions. Their score is shown in table 3 and figure 4. 


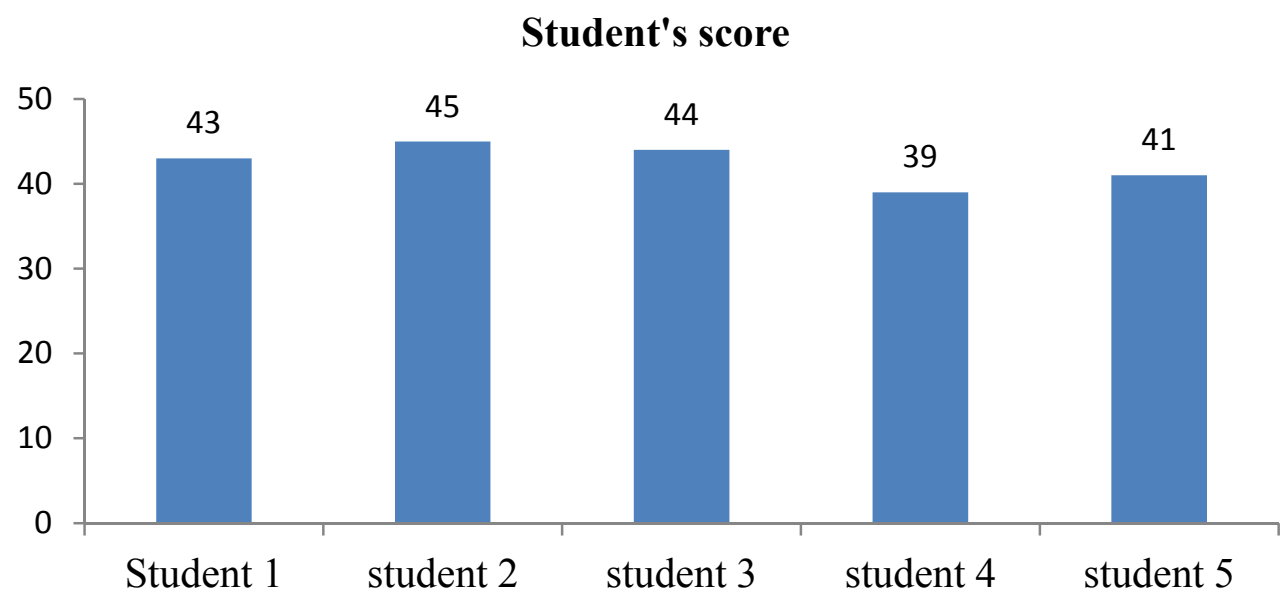

Figure 4 Students' score with approach 3

The graph shows the number of correct answers given by each student within approach 3. It can be clearly seen that the students did the test far better and the minimum score is higher than the maximum scores within approaches 1 and 2 (Figure 5).

Average score

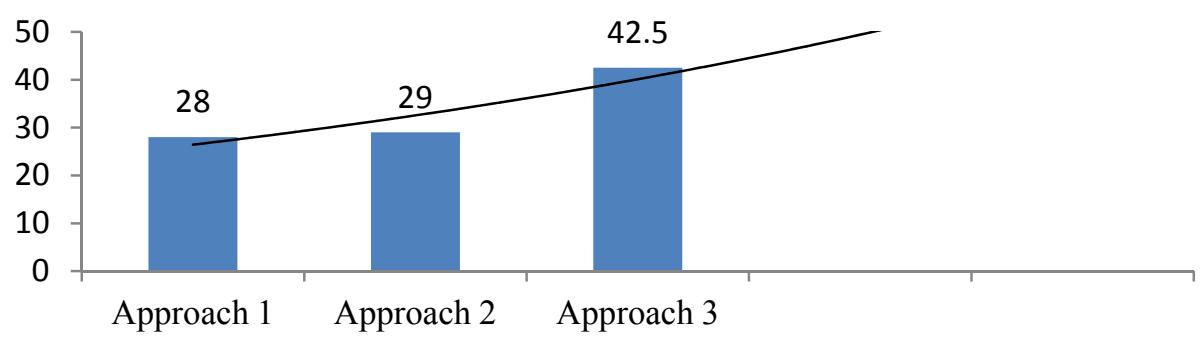

Figure 5 Students' average score

The graph shows the average number of correct answers given by the students within the three approaches. It can be clearly seen that the students did the test far better within approach 3. Having analyzed the scores obtained within the 3 approaches, it can be revealed that the best way of learning the English language is approach 3, where the topics were explained by a teacher and a computer in class. To sum up, the students learned faster and they scored better marks on the tests when they see the explanations not only on the board but also on their computer screen. 


\section{Internet resource}

The following website www.englishtests.webs.com, which was created by me, was used to carry out the research. It gives the endless source of material for teaching and learning the English language and several hyperlinks to test the knowledge of the English language on various aspects.

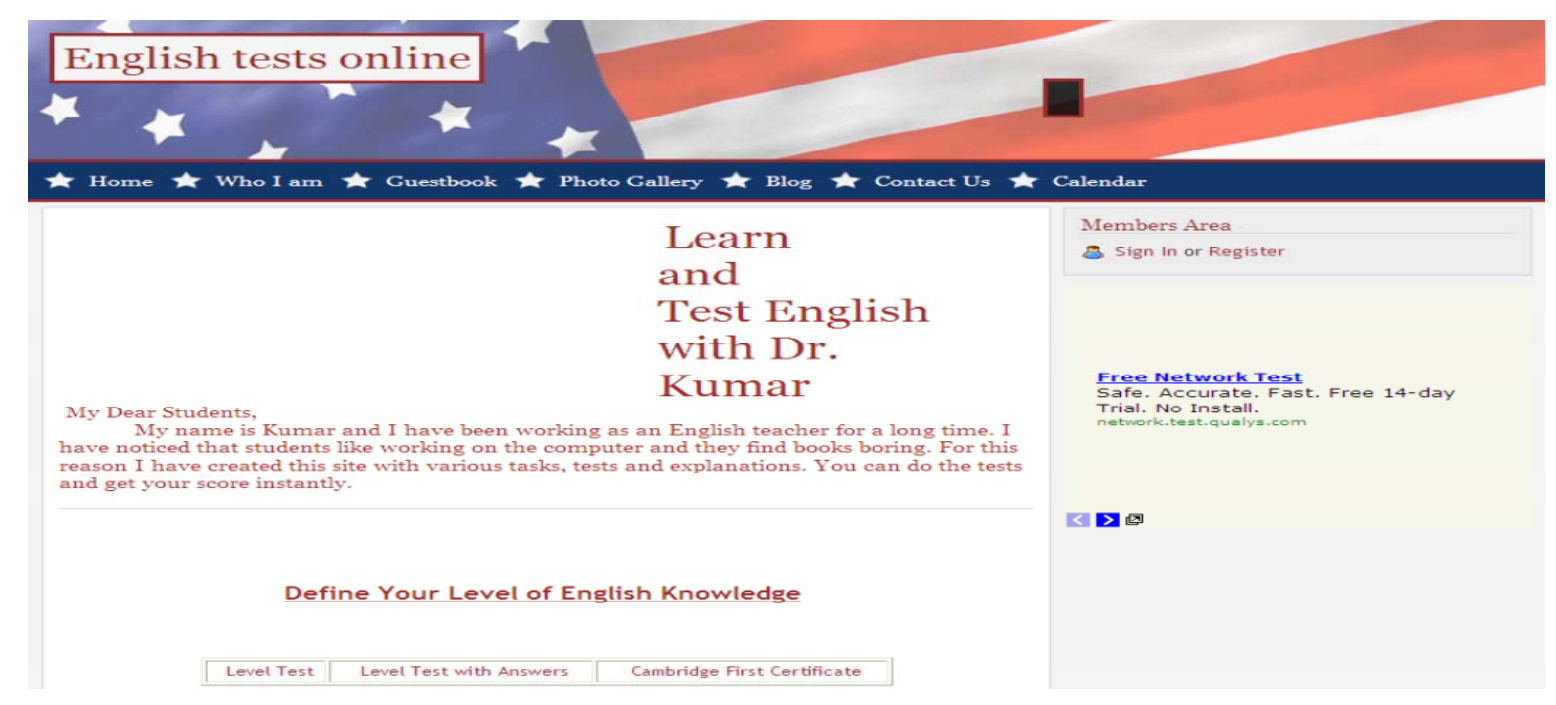

A screenshot of my websitehttp://englishtests.webs.com/

\section{How to use a computer in class}

Computers with internet resources can be used effectively in class if teachers follow the steps:

Select computer materials to be used i.e. a program or internet resources.

Plan the lesson. Teachers can decide on using internet resources to explain topics or taking online quizzes. The plan of the lesson also depends on the following: the size of class, intellectual maturity of students, student's motivation and course learning objectives(Agarwal, 2008).

Make the computer class ready before lessons. This means loading the computer with the chosen material ahead of time(Agarwal, 2010).

Divide class into several groups with at least one student who is good at computers and the language to be learned so that more experienced students can help the others.

Encourage students to use several online resources for the topic given and take online quizzes.

If online resources are not enough or do not make students understand the topic, a teacher should be always around to explain it using a classical approach(Agarwal, 2011).

Make students take as many quizzes on each language learning parts as possible. Ask students to submit their assignments electronically. 


\section{Need to use IBLL}

Having carried out the above-mentioned research, we have come to the following conclusion:

- Within IBLL students work with great pleasure on the computers as the language is given in different and more interesting, attractive ways through games, animated graphics and problem-solving techniques(Agarwal, 2009).

- Students are well-disciplined as the use of technology inside or outside the classroom tends to make the class more interesting.

- Students feel empowered and less afraid to contact others to realize their full potential as a team to accomplish their language acquisition tasks more effectively.

- Students become a leader instead of a teacher in class

- Students receive feedback immediately and they benefit from it.

- Some online quizzes explain students' mistakes, which make students understand the topic faster(Agarwal, 2010).

- Students are highly-motivated to use IBLL because they associated it with fun and games or fashionable.

- Students have time flexibility as they can use various resources of authentic materials either at school or from their home.

- Students feel independence from a Single Source of Information as the internet provides them with thousands of information sources(Agarwal, 2011).

- Students get greater interaction.

\section{Conclusions}

There is no doubt that the availability of modern internet resources provides not only students but also teachers with exciting possibilities for innovative challenges in the teaching and learning of the English language. The conventional classroom-based instruction doesn't provide the students with versatile knowledge because of lack of authentic materials and time but at the same time IBLL can solve all these problems. My own experience shows that students work in the classroom better and more efficiently when there is something connected with the modern technologies. In order to make students understand their teachers and actively take part in class activities IBLL is vital. By the way, the internet with its unlimited resources, will never replace language teachers, but it can make the English language and teaching more interesting and fruitful for both teachers and students.

\section{References}

1. Agarwal, M.Kumar, (2008). CALL- Advantages \& Disadvantages, RTU scientific proceedings, Riga, Latvia 
Proceeding of the International Scientifical Conference May $23^{\text {th }}-24^{\text {th }}, 2014$ Volume III

2. Agarwal, M.Kumar (2008). Teaching large classes with web technologies, Vilnius Business College scientific proceedings, Vilnius, Lithuania

3. Agarwal, M.Kumar, (2009). Models of Language learning and teaching with internet resources, ISMA scientific proceedings, Riga, Latvia

4. Agarwal, M.Kumar, (2010). Internet-based Language Learning and Teaching, Vilnius Business College scientific proceedings, Vilnius, Lithuania

5. Agarwal, M.Kumar, (2011). Teaching Large Classes with Web Technologies, TSI scientific proceedings, Riga, Latvia

Assistant Professor

Kumar M. Agarwal

Professor L. Novickis
RBS Riga Technical University, 11 Skolas Street, Riga, LV 1010

e-mail: kumar.agarwal@RBS.lv

Riga Technical University, 1 Meza Street, Riga, LV-1048

e-mail: Lnovickis@gmail.com 